\title{
Western Medicine in India as a Colonial Case in Amitav Ghosh's The Calcutta Chromosome
}

\author{
*SUKANYA MONDAL \\ RASHMI GAUR \\ Department of Humanities and Social Sciences, Indian Institute of Technology Roorkee, \\ Uttarakhand, India \\ *Corresponding author: mondal.sukanya@gmail.com
}

Published online: 20 April 2018

To cite this article: Mondal, S. and Gaur, R. 2018. Western medicine in India as a colonial case in Amitav Ghosh's The Calcutta Chromosome. KEMANUSIAAN the Asian Journal of Humanities 25(1): 1-18, https://doi.org/10.21315/kajh2018.25.1.1

To link to this article: https://doi.org/10.21315/kajh2018.25.1.1

\begin{abstract}
This paper focuses on the introduction of Western medicine in colonial India and its relationship with indigenous Indian medical practices against the background of Amitav Ghosh's The Calcutta Chromosome. It tries to locate an alternative narrative of the subalterns who, instead of conceding subordination, actually manipulate the state of the art of contemporary malaria research in early 20th century and reincarnate themselves in a futuristic New York but never let the elites discover their true motive. Simultaneously, it throws light on instances of epistemic violence because of cultural encounters.
\end{abstract}

Keywords and phrases: colonialism, South Asia, Western medicine, epistemic violence, knowledge

\section{Introduction}

The Ministry of AYUSH is formed in 9th November 2014 for providing more healthcare. The Department of Indian Medicine and Homeopathy (ISM\&H) was created in March 1995 and renamed as Department of Ayurveda, Yoga and Naturopathy, Unani, Siddha and Homoeopathy (AYUSH) in November 2003, with a view to providing focused attention to development of Education and Research in Ayurveda, Yoga and Naturopathy, Unani, Siddha and Homoeopathy systems. ${ }^{1}$

This statement, which is given as the running head of the website of the Ministry of AYUSH, India, sounds quite ironic if one looks at the colonial picture of health and medicine in retrospect. A nation/country that at one point in time faced an aggressive campaign in favour of embracing Western medicine in order to progress 
is now trying to uphold the traditions that it forgot in its journey. This motivational declaration of the Ministry was the inspiration for this research paper, which attempts to read Amitav Ghosh's The Calcutta Chromosome as a critique of the history of science. The book was published in 1995, and the author received the Arthur C. Clarke Award for this book in 1996. Ghosh tries to unravel a possible narrative in the history of science that can potentially deconstruct the accepted narrative of history. He delineates how scientific research, especially medical research, becomes a point of contention in the era of colonialism. Ghosh not only depicts research in Western medical science in colonial India but also presents how the folk healing system functioned at the same time. By reconstructing a possible counter history of malaria research in India, Ghosh tries to give agency to the unrecognised marginal people in the history of science whose contributions remained unsung in documented history. In addition, the complex relation between Western medicine/science and the traditional Indian healing practices that are available both in the higher rung of Indian social hierarchy and among marginal people is explored. How subtle moves towards establishing the Western system in all cases, e.g., medicine, learning and knowledge, gradually try to settle a hegemonic foundation of Western modernity in India is discussed. Furthermore, it is argued that knowledge produced in India has always been authenticated only by the parameters of the West. The story is not just about deconstructing the history of science; by mixing up different generic styles, Ghosh challenges the categorisation of different disciplines. The barriers between generic disciplines, even between religion and science, are often transcended. Daniel Headrick has described Western medicine as an expansionist tool of Western imperialism (Arnold 1993, 15). Gyan Prakash points to a relation between the formation of different disciplines of science and expanding Western imperialism (1999, 12-13). This paper attempts to examine the interface of science/knowledge, modernity and religious practices as these aspects are portrayed in The Calcutta Chromosome, especially the way in which the relation between Western medicine and Western imperialism against the background of malaria research in colonial India is unravelled. In The Calcutta Chromosome, the narrative is not solely temporally located during colonial time. Murugan, a medical historian in the novel, looks back at colonial research in the 1990s and, by producing circumstantial evidence of the time when Ross pursued malaria research, which is still available, tries to draw a credible story that counters the accepted documented history.

In several pieces of his writing, Amitav Ghosh discusses the inherent problem of the concept of modernity. Modernity, which is essentially a European concept, assumes an empiricist nature of knowledge. Anshuman A. Mondal observes that Ghosh highlights this particular characteristic of Western knowledge as a flaw. The problem in assuming knowledge to be essentially empiricist is that it discards 
everything that is not empirical (Mondal 2007, 42-43). In discourses outside the West, such as in India, empiricism is not ignored outright, but neither is it considered the foundational base. Because of the exclusive nature of Western science, the Indian tradition of knowledge is discarded. In support of the West's emphasis on empiricism and its lack in Indian tradition, Engler observes that in Indian tradition, arguments are rhetorical and not empirical $(2003,10)$. The indigenous traditions of healing practised by the subaltern people of the subcontinent "are not the historical prototype" of Western sciences, "nor their practical by-products" are, according to Michel Foucault, knowledge $(1989,183)$.

\section{Western Medicine as a Tool of Colonial Expansionism}

"Colonialism used - or attempted to use - the body as a site for the construction of its own authority, legitimacy, and control" (Arnold 1993, 8). Controlling diseases or, to be more precise, controlling epidemics became a way of controlling the body. In the colonies, medicine was thus not confined within therapeutic limits but crossed discursive boundaries and became a significant component of colonial politics. Not only with the surgical instruments used but also with its discourse and scrutinising gaze, the medical fraternity has a sort of hegemonic corporeal control over the body. The surgeons of East India Company, as Arnold observes, understood the rich variety of Indian diseases. Despite their own relative inaccessibility to mainstream European medicine, they felt that the transmission of knowledge is not necessarily unidirectional, i.e., from the centre to the periphery. Occasionally, it could be the other way around (Arnold 1993, 23).

Popularly, it is considered that Western medicine became an immediate hit from the moment of its entrance into Indian geography, but the real truth is slightly different. It was not the British colonial period that brought Western medicine into contact with the Indian medical system or the Indian population, and it was not an instant hit. Indian medicine, such as any branch of Indian civilisation, was exposed to the West through cultural exchanges between India and the West starting during the Indo-Greek interaction, according to documented history (Arnold 1993, 14).

In 1613, the Jesuit missionary Roberto Nobili included "Aiur vedam" in his list of the sciences of the Brahmins, and he drew an implicitly ideological line through each of the various scientiis quas Brahmans tractant (at this time, of course, "science" was a general term for a system of thought). Nobili sifted his sources for what he considered to be religion, and he found in the concept of Brahman a reference to the "one, true, immaterial God, at least as far as it was possible for him to be known through the natural light of reason" (Halbfass 1988, 40). Francoise Bernier collected aphorisms from Ayurvedic texts in the 17th century, 
and he commented that they were precise and rational (Arnold 1993, 45). Thus, the general claim that it was the introduction of Western medicine in India in the colonial era that enriched the Indian medical canon is not wholly true.

However, the introduction of Western medicine in India gave a new dimension to the relation between doctor and patient. A doctor has the power to intervene in the bodily functions of a patient. In that way, he has a special authority over the patient's body. The interaction becomes doubly complicated when the doctorpatient relation also fits into the coloniser-colonised frame, i.e., the doctor is a representative from the colonisers' race and the patient belongs to the colonised race. Moreover, in malaria research, there is an exotic element in it because of the disease's prevalence in tropical regions. In addition, controlling a person's physical well-being can be considered a means to controlling the person's body. Thus, the West, by acting as the physician, controls the body of the colonised race.

Foucault demonstrates that concepts such as "gymnastics", "exercise" and "musclebuilding" that are motivationally focused on the body, especially for children and soldiers, are actually means to control the body. He further asserts that Marxism, in order to emphasise consciousness and soul, relegated the body to the backstage of discourse, whereas in the age of capitalism, it is the body through which the state celebrates as well as wields its power (Foucault and Colin 1980, 56-57). In the same vein, it can be said that the control of contagion can be a form of controlling the body. Inoculation in the colonies was thus an attempt to overpower the body of the colonised. Thus, inoculation or any such state-sponsored health measure is an example of the administration's willingness to bring the body of the society, in this case, the colonised people, under its power.

When identifying a class that practises medicine, Western ethnographers document only the literature available among the practitioners of Ayurveda or Yunani, but there was a folk tradition of medicine practised by the community of Dom, barbers, and a few other communities. Fabrizio Ferrari observes that the vaidyas also gathered a huge repository of medical knowledge from farmers, herders, hunters, monks and jungle dwellers. Thus, unlike the Western tradition, the practice of medicine is not limited to professionals (Ferrari 2014, xxii). In The Calcutta Chromosome, we see that both Mangala and Lakshman who practice folk medicine, hail from the most humble section of society. Mangala is depicted as a sweeper woman working in Ronald Ross's laboratory, but she is actually a demigoddess revered by marginal people. Ghosh not only hints at the intertwined relation between medicine and religion in contemporary India but also shows that the Hindu pantheon is also not classless. In the novel, Mangala is the presiding goddess worshipped by the marginal people, and it is quite obvious that she is not worshipped by the uppercaste people. In fact, her name is also unknown to them. 
Colonial medicine or Western science has had a very complex relation with the indigenous Indian practice of folk medicine. The complexity is partly because of the almost inextricable association of medicine and religion in Indian context. There are a number of deities, mostly goddesses, who are considered to be the presiding deities of certain diseases in many parts of India. Interestingly, in case of the subaltern tradition of folk medicine, these deities are not the elite deities of the vast Hindu pantheon. Gods and goddesses such as Sitala, Mariamma, Manasa and Ghentu are believed to be the deities of certain diseases and illnesses by their devotees. In The Calcutta Chromosome, the way in which Amitav Ghosh describes the genealogy of Mangala resembles the origin of many gods and goddesses worshipped mainly by the subalterns of South Asia. As described in the novel, a middle-aged village woman finds a stone while bathing in a pond and the rural people impose divinity on it because of its miraculous power. The incident underscores the role of the subaltern people, who in spite of being marginalised by elite Hindus, create a sort of Hinduism that is vastly different from the ritualistic Hinduism practised by elite Hindus. Interestingly, just as the deities of the subalterns remained unknown or invisible to the upper-caste elite people, the subalterns themselves prefer invisibility. In The Calcutta Chromosome, the subaltern group functions in obscurity. The British scientists depended heavily on their subaltern assistants or orderlies for their experiments and study, but they rarely acknowledged the contributions of these marginal people.

The Calcutta Chromosome has become a more pointed critique of the historicism of science. In the documented history of the discovery of the malaria parasite and vector, the main actor is Sir Ronald Ross. His Indian laboratory assistants and the people on whom he tested his theory did not get any recognition. Even in his own memoir, Ross does not list all the names of his assistants, but it cannot be denied that without their support, Ross's success would have been an impossibility. In his interview with Paul Kincaid, ${ }^{2}$ Ghosh reveals that he finds from Ross's diary that it was Lutchman or Laakhan (a real character in The Calcutta Chromosome) who taught Ross the differences between various species of mosquitoes. In addition to offering such knowledge, the native lab assistants and people of such standing often offered their bodies for medical experimentation. In the novel, the use of an indigenous man's body by British scientists in exchange for money is mentioned quite sarcastically. While boarding in Mrs. Aratounian's house, Murugan has a hallucination of being transported to a past incarnation in which he was one of the people who British scientists used in their experiments.

[L]ying on a hard, hospital charpai, stripped, naked, watching the English doctor uncork a test-tube full of mosquitoes into his net. In his fist he still clutched the coins he had been given, at the hospital gates. He held on to them tightly, savouring their feel, their reassurance; they were so cool 
to touch, so hard-edged; they made everything so simple, so clean: a handful of coins, a rupee, for handing on the thing that lived in his blood, for safekeeping to the doctor (Ghosh 2009, 135).

This incident can be read as a violation of medical ethics by British doctors.

David Arnold observes that though the practice of Western medicine was limited to a few cities that were administratively important in colonial British India, it gradually gained popularity among middle-class Indians educated in the colonial system. What is unsaid here is that whatever amount of interest and enthusiasm the middle-class people harbour for Western medicine, they never volunteered their bodies for the experiments of Western medicine. The Western medical practitioners, by coming to India, actually found a wonderful pool of people on whom they could experiment freely. The body of the Indian subaltern, it seems, was always ready and receptive for such activities.

Thus, the initiation of Western medicine in India has multiple consequences. It was responsible for reviving the age-old indigenous Indian medical practices. Sometimes they simulated the Western medicines and sometimes were in competition with the Western medicines which motivated their revival (Arnold 1993, 29). Arnold also observes that initially Europeans depended mostly on Indian medical practitioners, thinking that they were more knowledgeable in the matters of diseases caused in this particular land and climate $(1993,35)$. What is most intriguing is the twofold nature of the relation between Western medicine and India. There are two interfaces here. The first one is between the indigenous medicinal practices and the Western medicine. Another interface is between the Western medicine and the Indian body, to be more precise, the coloniser's medicine and the colonised's body. There is a distinct gaze of the coloniser even when they experiment with the native Indian's body.

The elite, urban section of Indians kept themselves aloof from Western medicine as long as possible. Thus, it is only the lower caste, lower class Hindu and Muslim population who British doctors and scientists found at their disposal. Here, it should be noted that the colonial judiciary put the utmost importance on written documents. Warren Hastings, one of the earliest British administrators who voiced the importance of building a knowledge bank of India, stressed using written documents (Cohn 1985, 315). As a result, in the writing process of India's history and formulating personal laws for both Hindus and Muslims, only written religious scriptures were taken into account (Mani 1987, 122). Naturally, the persons who were consulted were either Hindu Pundits (Brahmins) or Ulema (Muslim theologians). Consequently, the marginal people of either community had 
very little or no representation at all in colonial written documents. The elite, as some historians argue, were first to receive the opportunities of colonial education system and built a resistance against colonialism. Because of this resistance and their mark in various colonial systems, especially academia and administration, the native elite people had some representation, compared to the marginal natives (Barrow and Haynes 2004, 472).

\section{The Claim of Logic and Empiricism in the Post-Enlightenment Western Tradition of Knowledge}

Ghosh writes a great deal about the history of science, especially the history of this particular discipline. In both The Circle of Reason and The Calcutta Chromosome, it is observed that there is a partisan approach of history favouring the dignitaries of scientific knowledge. In the history of science, there were a few branches of sciences, such as phrenology and criminology, that gained popularity for certain period of time but were later proved to be baseless. Specialisations such as virology or mycology proved to be solidly established on realistic theories. However, in the documentation of history, importance always gravitates towards the latter. The people whose scientific endeavours did not bear fruit are rarely mentioned in history. Thus here also it is the history of victors. In both The Circle of Reason and The Calcutta Chromosome, Ghosh mentions these so-called pseudosciences. The very origin of pseudosciences actually proves the arbitrariness of science.

While giving multiple examples of how arbitrary and fateful the field of experimental science is, Ghosh draws a picture of how the lower caste marginal people of colonial India were carrying on with their practice of folk medicines. The principal difference between the Western mode of research and the Indian subaltern system is that whereas recognition of certain knowledge is highly desirable in the Western system, in the Indian system, people generally did not care much for the social recognition of their findings. This is the reason that there are many texts written in ancient and medieval India that do not bear the names of writers. It is often alleged by the Western scholarship that there is no history (the discipline as defined in the Western system of knowledge) of India. In the Western tradition, the inextricable relation between knowledge and literacy is a primary factor that makes the West vastly different from the Orient. In the Indian tradition, writing exists but the oral tradition is also very highly esteemed. The subaltern traditions (e.g., the tribals) are still chiefly oral. Even considering the high caste elite Hindu tradition, the Vedas were not written originally. All the mantras in the Rigveda were recited only, and the Samaveda is chiefly the compilation of the rules of chanting the mantras of the Rigveda. The unwillingness to document one's findings or let others know about this partly explains the absence of history in 
precolonial India. Hegel attributes this lack of history to the Indians' not having a concept of nation (Guha 2002, 52). The group of scholars who have been working in the field of subaltern studies are working to untwine history from the concept of nation. In spite of this association of history with nation, nation is a modern subject altogether and as a discourse, it is very much a European concept. The appreciation of knowledge is different in the Indian and Western traditions. Edmund Husserl, in his comparative study of Oriental and Western science and philosophy, asserts that Greek-European science is more universal and purely theoretical in nature, while the former is mythical-religious (as expounded by Dipesh Chakrabarty in his essay on Indian pasts 1992, 3). Such an estimation of Indian traditions of knowledge by Western scholars resulted in the waning of funds (by private as well as government agencies) provided for the study of the oriental subjects in colonial India.

The funds and arrangements for the study of Ayurveda and Yunani or, to be more precise, the Indian medical practices were no longer sanctioned after 1835 throughout the colonial regime. Similar to other supercilious Anglicists, T.B. Macaulay gives his vitriolic opinion in this matter. He observes that funding the study of Indian subjects was a waste of tax-payers' money because,

Medical doctrine which would disgrace an English farrier, astronomy which would move laughter in girls at an English boarding school, history abounding with kings thirty feet high and reigns thirty thousand years long, and geography made up of seas of treacle and seas of butter (Macaulay 1835).

At the time of the establishment of British rule and their education system, the British administrators actually found eager supporters from the Indian civil society as well. Rammohan Roy, who is widely regarded as the father of modernity in India, wrote a lot in support of the establishment of a full-fledged Western education system. His emphasis on the essential requirement of "Mathematics, Natural Philosophy, Anatomy, Chemistry, and other useful sciences" [emphasis added] (as quoted by Rapson 2015, 105) for the foundation of the colonial education system in India implies his underestimation of the existing or ancient education system of India. It means that he did not consider the subjects taught in the then indigenous academia to be useful. It reveals his contempt for the uselessness (if it is so) of subjects of Indian academic discourse. Here, the crux of the problem is not Western education but the Western tendency to reject everything Indian as irrational. The problem in the pedagogical acceptance of history as a secular subject only is that it risks forgetting or removing many aspects that are generally considered non-secular, such as gods, spirits, superstitions, and pagan rituals. Dipesh Chakrabarty elucidates that their existence does not depend on the belief of social scientists, but they claim their existence because of human practices 
(2007, 111). Amartya Sen makes three divisions of the ways in which Western scholars estimate Indian culture - "exoticist approach", "magisterial approach", and "curatorial approach" (2006, 141). The magisterial approach serves as an excuse in support of the colonisation of India because scholars (e.g., James Mill, Thomas Babington Macaulay) taking this approach dismiss any claim of Indians to significant scientific or artistic contribution to human civilisation (Sen 2006, 147). This tendency to not acknowledge the seriousness in the body of research and knowledge produced in India points to the West's Orientalist assumptions about India.

Ghosh questions the hegemony of the West on modernity. By juxtaposing the subaltern healing system of India with the Western colonial medical system, this argument is accentuated. In The Calcutta Chromosome, Western science is hybridised at the hands of the Indian lab assistants working for British scientists. Arnold extensively discusses the dialogic relation between Western and indigenous Indian medicine during the colonial period. He argues that both underwent transformations and hybridisations $(1993,14)$. The cultural hybridisation on the part of the colonisers is evident in British administrators' establishment of different hospitals for different castes of people to make Western medicine acceptable to orthodox Indian society (Arnold 1993, 250). It can be considered an incentive for Western medicine, so it can gradually establish a hegemony over the rest of the healing systems of the country. In case of Ayurveda and a few other healing systems, such a casteist practice was prevalent. Thus, though the Western scholars flaunted of science being secular, when it came to the practice of that science in India, they too did as the Indians used to do.

Science is often considered one of the precursors of modernity, but Ghosh shows that similar to modernity, science can also evolve without the hegemonising influence of the West. The kind of structural methodology the West has that prescribed for science is not accepted as a fool proof method by Ghosh. The question that Murugan asks Antar sets the tone of The Calcutta Chromosome: "Do you think that everything that can be known, should be known?" (Ghosh 2009, 52). The subaltern practitioners of medicine believe that to know something is to change it. In the novel, Murugan explicates an alternative way of exploring science: "Think of Ramanujan, the mathematician, [...]. He went ahead and reinvented a fair hunk of modern mathematics just because nobody had told him that it had already been done" (Ghosh 2009, 209). Murugan suggests that Mangala's feat in the field of scientific experiment is exactly like that. She has chosen an alternative path to work in the field of malaria research. She could do it more freely because she was not trained in the conventional Western method of science, and thus, is not tied down by its crippling restrictions: "She wasn't carrying a shit-load of theory in her head, 
she didn't have to write papers or construct proofs" (Ghosh 2009, 244). There is an oblique reference to the coincidental breakthroughs of scientific discoveries here. Many inventions were actually fortunate coincidences, and scholars had to erect theoretical frameworks to produce them as proofs later.

Many inventions and discoveries in science occurred by chance, such as the discovery of antibiotic property of penicillin or Pasteur's vaccine for hydrophobia. In The Calcutta Chromosome, it was subtly proposed that Ross's discovery in the pursuit of malaria parasite too was such a fluke, at least on the part of Ross. As nothing is happening in the world in this particular field and even Ross's research has not been producing impressive results, he suddenly finds someone (Abdul Kadir in The Calcutta Chromosome, a real person living at the time of Ronald Ross) whose blood sample discloses exemplary phenomena under the microscope. In the novel, Murugan suggests that it is not Ross who hand-picked Abdul Kadir but rather that Abdul Kadir actually chose Ross. Thus, Ghosh gives a unique example that makes us revise our general assumption about the network of power in South Asian social hierarchy. It is commonly assumed that it is the economically more powerful class that determines how the lower and less powerful sections move or act. In this novel, it is suggested that a group of marginal people was already working on malaria when Ross begins his research. Because of their marginal social status, the group does not publicise their findings. They achieve substantial success in understanding the nature and reactions of Plasmodium falciparum, but they are stuck at a certain point and cannot get over it. At the very moment they find Ross and feel that because of his knowledge of and access to a certain experimental sophistication, he could transcend this deadlock. Contrarily, Abdul Kadir, almost a non-entity compared to Ronald Ross according to his social or economic power in colonial India, actually manoeuvres Ross's experiments, but Ross never realises that he is being manipulated. Thus, Ghosh shows that the agency of the subaltern may occasionally be so subtle as to create the illusion of nonexistence.

It is interesting to note here that Indian society has often been subject to severe criticism because of its myriad caste divisions, but when the West was involved in experimental research, especially in medicine, it relied on the exploitation of the casteist divisions of the native society. Ideologically, the colonisers castigated caste divisions, but both the upper caste Hindu society and the secular British scientists depended on the people who lay in the fringes of the society. Both the Europeans and low-caste people did not have free accessibility to the sphere of the elite castes, but gradually the white people paved a way through their technological, economic and military prowess. Although the Europeans did not completely subscribe to the elite people's ideas about the marginal castes, they relied on these people for the baser jobs in daily life. Thus came this odd combination - the white man's medicine 
and the polluted people. The low caste people's (namely, the community of Dom) ${ }^{3}$ indispensableness was primarily in the mortuary. From pre-colonial times, the men of this caste traditionally cremated the dead bodies, and the women served as midwives. Thus, the lives both of men and women were very close to the human body, yet this proximity elicited such a strong aversion in the so-called higher caste people that their touch was avoided in the time between birth and death. Therefore, it is not unusual that because of their dealing with birth and death, they had certain knowledge about the application of some indigenous medicines and herbs. Although they are never allowed to touch the body or come near it in normal situations, they are the only people who the practitioners of the Western medicines found available to help them in the dissection room.

In regard to writing the history of the colony, colonial scholars did mention the caste system and the complexity of it due to aversion and domination, but did not care to document the medicinal practices seriously. This subject is referenced as a part of the Oriental mumbo-jumbo. Benjamin Heyne suggests cultural differences as a cause, with the Oriental texts, especially the medical ones, impossible for Europeans to translate into European languages. The aphorisms, recurrent use of allusions (which sometimes are religious), and mentions of rituals make the texts unintelligible for Europeans. Moreover, Heyne specifically mentions the poetic style of writing as another reason for the difficulty in translation and understanding $(1814,125)$. In addition, the review of Oriental medical practice was not limited to linguistic or cultural differences but also encountered different types of medical practices. In addition to the Ayurveda and Yunani traditions, there were groups of subalterns (especially from the Dom community) who provided certain remedies for ailments, but these practitioners knew only the practical usage of their remedies and did not have any theoretical knowledge. This is another point that European scholars mock.

Thus, the lack of conventional institutional knowledge or tradition among the subaltern medical practitioners elicited European scholars' derision of the folk medical tradition of India. In The Calcutta Chromosome, the primary concern of the secret subaltern group of malaria researchers was theoretical knowledge. This issue has been addressed by William Twining, who did some research on malaria in Bengal in the early 19th century:

The natives of this country generally use remedies in any disease, from practical knowledge of their efficacy, without much reasoning; therefore, I would not reject any of their therapeutical expedients as despicable, without an enquiry into their, and an experimental modus operandi, and an experimental investigation of their utility (as quoted by Arnold 1993, 51). 
Thus, the scholars, some of whom worked in the medical discipline, regarded India to be not worthy to be mentioned and gave a generalised offhand view about the diseases of the land. Their judgement was, most of the time, derived from books written about India or simply fabricated. However, a number of medical practitioners, although they were estranged from the mainstream medical science of West due to geography, considered their career in India to be a great opportunity to learn about a considerable variety of ailments. Morehead, who once dismissed the singularity of India as an interesting domain of medical research, later observed:

Habit, food, and climate exercise indisputable influence upon the human system, both in a healthy and diseased state; and it is equally important to pathology and physiology, to determine the modifications which they induce, and the varieties that may be attributed to their operation, in a country so different as India, both in its physical and social relations, from those regions in which medical observation has been hitherto most extensively engaged (Arnold 1993, 20).

While the British administration in India set up a system to combat certain diseases, it cannot be denied that the British colonisers themselves had particular contribution to the spread of malaria. There are many references to railways in colonial India in The Calcutta Chromosome. This iron network no doubt united the whole country geographically, but similar to irrigation, this was another means for colonisers to enhance the collection of revenues and raw materials from the jewel on the crown. Naturally, all the references to railways, such as the ghostly incident at Renupur station or the motif of a railway signal lantern, remind one of a diabolically material cunning behind the establishment of the railways in India. Western technology, specifically the railways in India, literally served as a form of colonial expansionism. Malaria occurred in India before the British came, but with the aggressive networking of irrigation systems to boost agricultural yield and industrialisation in cities such as Calcutta and Bombay without any serious attention to the hygiene of the workers' quarters, the disease became more frequent and spread to pockets of the country where it had been hitherto non-existent (Packard 2011, 87-88).

\section{The Epistemological Differences in Indian and Western Systems of Knowledge and Science}

The basic condition of the claims of truth that history or historiography demands are reasons and evidence. Archaeological or archival evidence is produced to support what historians speak or write about a certain time, incident or person of the past. The basic fallacy in this system of knowledge is that if there is nothing as such that can be produced as an evidence, an incident or phenomenon is considered 
fictitious. Most of the time, the history that we read as the text is either economic or political, and it is always written by the literate elites of the society. Thus, there is only one cultural perspective of history. Rarely are the marginal people given a role. They are, in the language of film, always in the crowd scene - groups of faceless non-entities. Thus any sort of cultural practices or ethnic characteristics of these people go unmentioned in the documented history. Consequently, when the colonisers took up the job of building a knowledge bank about the colonised land, they did not include information related to the marginal low caste people. It should be noted here that the traditions of the subalterns in India have always been carried on orally. Thus, although some scholars were interested in retrieving Oriental culture and tradition, they unknowingly overlooked the culture of the subalterns because they primarily studied whatever was available in text.

Lou Ratte observed that the genealogy of science as described in The Calcutta Chromosome and The Hungry Tide shows that the scientific discoverers of the West became renowned in the colonised lands $(2012,19)$. No doubt their inventions are very important in the history of human civilisation, but the way these scholars are mentioned in the archival documents without the least mention of any indigenous tradition of knowledge in the respective fields suggests that these lands were a veritable "tabula rasa" regarding scientific discourse before Western colonisation. Ghosh, by giving examples that prove the arbitrary nature of scientific discoveries and exploring the possibilities of scientific traditions prevalent in the subaltern people of India, substantiates the argument that in India, there were indeed several medical traditions before the colonisers' arrival, and because of this practice, the native subaltern who aids the English doctor in the mortuary or in the lab is not as ignorant as s/he is described to be in contemporary English texts.

In this novel, the group of subaltern people who surreptitiously work to find a cure for malaria and syphilis believe in letting some epistemic detail of the whole body of knowledge remain unknown. They take it as a sacrilege to know everything. This trait reflects a general trend in the Indian body of knowledge at that time. In contrast, in Western tradition, generally any scientific claim stands on solid empirical ground. Ghosh here again points to the arbitrary randomness of scientific discovery. Murugan narrates a long story in which it is seen that the discovery of malaria parasite in a mosquito is a fluke. Louis Pasteur's biography states that he discovered a cure for cholera by chance. His assistant forgot to put the sample bacillus in the cupboard and instead left it exposed to the sun. Then, Pasteur injected some cholera-infected chickens with this culture. The chickens were cured. Although in documented history, all credit is given to Pasteur, but one can construe from the actual sequence of events that Pasteur had very little to do with the whole process. His lab assistant who unknowingly generated the cure remained unnoticed. 
Because of methodological differences between the conditional understanding of knowledge in Indian and Western systems, Western scholars, while documenting the history of Indian medical system, or any other discipline for that matter, described it as grossly fantastic. In The Calcutta Chromosome, when patients in their last stage of syphilitic dementia are brought to Mangala, and Farley's prying eyes observe, his quick judgemental reaction to the whole arrangement is that the quackery could not yield anything (Ghosh 2009, 130). Farley is one of those scholars who, when judging any aspect of another culture audaciously, come to a pejorative conclusion just because of the different cultural context. Any system that they cannot decipher or understand, they label as irrational/unscientific/quackery. Another difference between the West and Indian ways of thinking is that the discourses were not thoroughly compartmentalised in India. The compartmentalisation of different disciplines was primarily done in Europe. In his interview with Chitra Sankaran, Ghosh states that European scientists depended heavily on their native informants while compiling books on natural sciences (Sankaran 2012, 8). He further maintains that, following this Indian tradition, he does not believe in the compartmentalisation of knowledge either. Even science and religion are not too contradictory to him. To him, the very concept that motivated J.C. Bose to examine the response system in plants is a concept of Advaita (Sankaran 2012, 10). In fact, within his novels, by crossing generic borders often, Ghosh reminds us of the Foucauldian doubt about the distinct classifications of discourses. Foucault questions the validity of any distinction between the principal types of discourses. He further affirms that the generic differentiations imposed on disciplines such as science, religion and literature are questionable (Foucault 1989, 22).

Sankaran, in her essay on The Calcutta Chromosome, discusses how Ghosh presents a possible alternative of the normativity acknowledged by the Western system of logic. The difference between the Western normativity and the possible Other is so great that they cannot be assimilated. In this novel, we see that the Other even challenges the linearity of time. Moreover, the certainty of how the European system of knowledge sits within the pedagogical frame is also contested. In this novel, Urmila refers to one of Phulboni's stories in which Phulboni describes the discovery of a stone figurine by a drowning woman and the deification of that statute. Later, he finds images of the same figurine described in his story being sold in Calcutta. He is convinced that these sellers or the potters do not know about his story. They introduce the image as the deity called Mangala. The myth or story associated with this image that the seller narrates resembles Phulboni's narrative completely. Thus, Phulboni is confused about the inception of the whole idea his story or the construction of the Mangala myth. At this point, the moment of inception of this particular story written by Phulboni becomes hazy. 
In addition to the basic differences in understanding knowledge in the South Asian and Western systems, Ghosh also shows that it is not only that the Western scholars did not try to understand the multiple layers of Indian culture due to their assumptions things about the Other, but parts of the indigenous cultural body themselves chose to cocoon their identity. In the novel, the subaltern group's illiteracy, their dull look and their unimpressive attire collectively work as a veneer covering their true identity, motive and mission. This condition can be identified as analogous to Joan Riviere's critique of Jacques Lacan's theory describing woman as lacking the phallus. Lacan describes woman as one lacking the phallus and therefore womanliness is equated to the absence of strength. Riviere counters this theory by depicting womanliness as a mask. She thus introduces a much more complex theme in psychoanalysis by not portraying woman as lacking in something, but as a disguised competitor of man (Homer 2005, 100-101). Ghosh makes his subaltern characters don the same attire of dullness. When someone such as Farley becomes over-inquisitive and tries to poke his nose into these people's activities, they become very alert. When Farley first comes to Cunningham's laboratory, he happens to see a lowly woman in cheap sari and a native man in a laboratory shirt. As usual, Cunningham does not introduce them (Mangala and Lakshman) to him, thus demonstrating the social status they possessed at that time. They are not even considered to be worthy of an introduction, but Farley senses that he is being measured by them, which gives him an uncanny feeling. As soon as Farley understands that the power equation between the elite and the subaltern (in this case, the British scientist and his native illiterate lab assistants) is not as simple as the elite people think it is and that the subaltern people use their subalternity as a veneer covering their manipulation of the elite, Farley is killed. At this point, Ghosh shows how the divide between the upper-class urban sensibility and the belief system of the so-called rural uneducated mass is accentuated when the latter transcends the boundary of Western logic. In another instance, when Phulboni wakes up after the fateful stormy night, the station master of Renupur (who would later be revealed to be non-existent) attempts to tell a terrible story associated with the station, but at the same time, he observes that Phulboni would not have believed it had he told him earlier: "I tried to tell you but you wouldn't listen ... A big sahib like yourself. I can only tell you what people say in these parts: simple village people like myself" (Ghosh 2009, 237). It can easily be noticed how he underscores the cognitive differences between the urban and rural people. The same doubt is reiterated later by the guard of the returning train. When asked by Phulboni why he has not warned him about the notoriety of the Renupur station, the guard almost reiterates the ghostly station master: "I tried to ... but you would not have believed me. You would have laughed and said, "these villagers, their heads are full of fantasies and superstitions" (Ghosh 2009, 238). Here, the divide between Phulboni and the unreal station master or the train guard may be thought to have reached a stage of Lacanian uncanny. Phulboni's job 
and his Western education have given him a confidence that sounds like almost a bourgeois arrogance that defies anything outside its acknowledged episteme. In this case, the rural uneducated person knows the limits of the urban and lets the urban person step into the realm of the unknown that he (the urban) normally avoids. The exposure pushes Phulboni to a near-death situation that "effaces the distinction between imagination and reality" (Dolar 1991, 12). However, whatever happens or the stories the guard tells him are not too unfamiliar to Phulboni's imagination. In the whole episode, the subaltern other actually sort of jeers at the narcissistic and exclusive upper class urban culture.

\section{Conclusion}

Ghosh demonstrates how multiple and widely opposing systems of knowledge may exist in a particular spatiotemporal setting through the different subplots of The Calcutta Chromosome. He does not argue against the Western system of knowledge or the post-Enlightenment European tradition of logic and knowledge; his warning is against the suppressive doctrine that the carriers of this system of knowledge disseminate later on in different parts of the world and consequently destroy indigenous systems. Ghosh actually presents and makes the readers aware of the instances and possibilities of epistemic violence because of cultural encounters. He also warns of the danger of setting a specific normativity because this particular normativity constructs a reference frame that pushes all things that do not match the normative one to the fringes. He also asserts that the reticence or silence of the subaltern or the marginal may not always be a sign of their powerlessness. Rather, the silence may work as the desired guise of the saboteurs. In The Calcutta Chromosome, Ghosh attempts to present the folk medical tradition in a different way than the hegemonic tradition of the West does.

In the novel, the protean method of reincarnation through which the primary characters of the secret subaltern cult practising medicine reincarnate themselves has a unique characteristic. What is retained through this protean change is the memory and the legacy of their work and ritual, not the blood. Thus, although the Mangala Bibi myth primarily generates in a common village of Bengal, the latest reincarnation of the deity is in America. Laakhan, the untouchable village boy, is reincarnated in Antar, an Egyptian migrant in the US. The bodily incarnations of these characters may be interpreted in two opposing ways. Through these incarnations, they temporally carry on the legacy and agency of the medicinal tradition of the South Asian subalterns, but at the same time the process may suggest a loss of identity. Interestingly, Antar, Maria and Tara - all the futuristic reincarnations of Laakhan, Sonali and Urmila (who is actually the leader of the cult, Mangala) - can be collectively called a deracinated class, migrating to the first world from the third world. 
Returning to the introductory statement of this essay, the current measure taken by the Ministry of AYUSH, the government of India should be regarded as an endeavour to revive the indigenous medical traditions. The Western system of medicine (which is popularly known as allopathy) is no longer deemed as invasive or alien either by the masses or the government. However, the government is proactively stopping the erasure of the destruction of the indigenous medical traditions that began with the invasive propagation of Western medicine in the colonial period.

\section{Acknowledgement}

The authors would like to thank Ministry of Human Resource Development, Government of India for funding this research paper.

\section{Notes}

1. The Ministry of AYUSH website link is available at http://ayush.gov.in/ (accessed 20 August 2017).

2. Ghosh, A. Interview by Paul Kincaid. https://ttdlabyrinth.wordpress.com/2013/08/27/ reprint-an-interview-with-amitav-ghosh/ (accessed 20 August 2017).

3. David Arnold observes that they were referred to as "doms" without any upper case first character even by the British. It evinces their lack of power in society.

\section{References}

Arnold, D. 1993. Colonizing the body: State medicine and epidemic disease in nineteenthcentury India. Berkeley: University of California.

Barrow I.J. and Haynes, D.E. 2004. The colonial transition: South Asia, 1780-1840. Modern Asian Studies 38(3): 469-478. https://doi.org/10.1017/S0026749X03001203

Chakrabarty, D. 1992. Postcoloniality and the artifice of history: Who speaks for "Indian" pasts? Representations 37(Winter): 1-26. https://doi.org/10.2307/2928652

2007. Provincializing Europe: Postcolonial thought and historical difference. New Jersey: Princeton University Press.

Cohn, B.S. 1985. The command of language and the language of command. In Subaltern studies IV. Writings on South Asian history and society, ed. R. Guha, 227-252. Delhi: Oxford University Press.

Dolar, M. 1991. "I shall be with you on your wedding-night": Lacan and the uncanny. October Vol. 58, Rendering the Real (Autumn): 5-23.

Engler, S. 2003. "Science" vs. "religion" in classical Ayurveda. Numen: International Review for the History of Religions 50(4): 416-463. https://doi. org/10.1163/156852703322446679

Ferrari, F.M. 2014. Religion, devotion and medicine in North India: The healing power of Sitala. London: Bloomsbury. 
Foucault, M. and Colin G. 1980. Power/knowledge: Selected interviews and other writings, 1972-1977. New York: Pantheon.

Foucault, M. 1989. The archeology of knowledge. London: Routledge.

Ghosh, A. 2009. The Calcutta chromosome: A novel of fevers, delirium \& discovery. New Delhi: Penguin India.

Guha, R. 2002. History at the limit of world-history. New York: Columbia University Press.

Halbfass, W. 1988. India and Europe: An essay in understanding. Albany, NY: State University of New York.

Heyne, B. 1814. Tracts, historical and statistical, on India; with journals of several tours through various parts of the peninsula; also, an account of Sumatra, in a series of letters. London: R. Baldwin and Black, Parry and Company.

Homer, S. 2005. Jacques Lacan. London: Routledge. https://doi.org/10.4324/97802033 47232

Macaulay, T.B. 1835. Minute by the Hon'ble T.B. Macaulay, dated the 2nd February 1835. http://www.columbia.edu/itc/mealac/pritchett/00generallinks/macaulay/txt minute_education_1835.html (accessed 1 February 2018).

Mani, L. 1987. Contentious traditions: The debate on sati in colonial India. Cultural Critique No. 7, The Nature and Context of Minority Discourse II (Autumn): 119-156.

Mondal, A.A. 2007. Amitav Ghosh. Manchester: Manchester University Press. https://doi. org/10.7228/manchester/9780719070044.001.0001

Packard, R.M. 2011. The making of a tropical disease: A short history of malaria. Baltimore, MD: Johns Hopkins University Press.

Prakash, G. 1999. Another reason: Science and the imagination of modern India. Princeton, NJ: Princeton University Press.

Rapson, E.J. 2015. The Cambridge history of India (e-book). New Delhi: Facsimile Publisher.

Ratté, L. 2012. Unlikely encounters: Fiction and scientific discourse in the novels of Amitav Ghosh. In History, narrative, and testimony in Amitav Ghosh's fiction, ed. C. Sankaran, 17-32. Albany: State University of New York.

Sankaran, C. 2012. History, narrative, and testimony in Amitav Ghosh's fiction. Albany: State University of New York.

Sen, A. 2006. The argumentative Indian: Writings on Indian history, culture, and identity. New Delhi: Penguin India. 